https://doi.org/10.7203/Normas.2.4659

\title{
NOVEDADES LÉXICAS EN REVISTAS FEMENINAS: PROCEDIMIENTOS DE FORMACIÓN Y VALOR SEMÁNTICO- PRAGMÁTICO DE LAS UNIDADES*
}

\author{
LEXICAL INNOVATIONS IN WOMEN'S MAGAZINES: FORMATION PROCEDURES \\ AND SEMANTIC-PRAGMATIC VALUE OF THE UNITS
}

\author{
María ESTORNELL PONS \\ Universidad Católica de Valencia
}

\section{RESUMEN:}

El presente artículo pretende mostrar una de las particularidades léxicas de determinadas revistas femeninas, como es la creación de unidades y el uso de voces nuevas formadas con diferentes mecanismos patrimoniales o con la combinación de elementos patrimoniales y foráneos. A partir de un corpus elaborado, se presentan y analizan distintas voces desde el punto de vista de su formación y de su valor semántico-pragmático en el texto. Asimismo, se observa el aspecto de la marcación tipográfica de las unidades, en relación con la norma del español.

PALABRAS CLAVE: creación léxica, neologismos, revistas femeninas, formación, función discursiva, marcación tipográfica.

\section{ABSTRACT:}

This paper aims to show one of the lexical peculiarities of certain women's magazines, such as the creation of units and the use of new words formed with different native mechanisms or a combination of native and foreign elements. Based on a corpus that was developed, different voices are presented and analyzed from the point of view of their formation and their semantic-pragmatic value in the text. In addition, the aspect of typographical marking of the units in relation to standard Spanish is observed.

KEYWORDS: lexical creation, neologisms, women's magazines, mechanisms of formation, discourse function, typographical marking.

* Investigación inscrita en el marco del proyecto FFI2011-24712, Análisis léxico y discursivo de corpus paralelos y comparables (español-inglés-francés) de páginas electrónicas de promoción turística, financiado por el Ministerio de Ciencia e Innovación, coordinado por la Dra. Julia Sanmartín.

NORMAS. REVISTA DE ESTUdIOS LINGÜÍSTICOS HISPÁNICOS, NÚMERO 2 (AÑO 2012):

http://www.uv.es/normas

(ISSN 2174-7245) 


\section{INTRODUCCIÓN}

En los textos de determinadas revistas femeninas se observa la presencia de un léxico particular relacionado con el carácter y finalidad de este tipo de discurso. En concreto, se trata de revistas de alta gama como Woman, Glamour y Cosmopolitan, dirigidas a mujeres entre 20 y 35 años aproximadamente, de clase media, para las que se presentan las últimas tendencias de la moda y diversas opciones de compras, consejos de belleza y cuidados personales o de salud, reportajes sobre algún tema de actualidad (en relación con espectáculos, cultura, artistas, novedades en la sociedad...), información y sugerencias sobre viajes y otros planes de ocio, recomendaciones para relaciones sentimentales, o ideas sobre decoración y gastronomía... Esto es, temas marcados con el sello de femeninos (Torres, 2007: 219), que se encuentran repartidos en distintas secciones ${ }^{1}$, si bien la información sobre moda y belleza es la que más páginas ocupa en las tres revistas citadas.

Estas revistas, por tanto, promocionan novedades y tendencias en diversos ámbitos, para un público determinado, y persiguen captar la atención e identificación de las lectoras. De ahí que su discurso responde a dicho fin promocional y empático, y presenta determinadas características como el uso de ciertas unidades léxicas, el tono informal, moderno y juvenil de muchas de sus páginas, o el estilo persuasivo y altamente expresivo de algunas secciones.

El presente trabajo se ocupa del aspecto léxico de estas revistas, cuya particularidad reside en el uso de distintos tipos de unidades que responden a diferentes funciones discursivas y procesos de formación. Para analizar tales unidades, se ha partido de su plano formal. Así, en un trabajo paralelo se ha tratado una clase de voces recurrentes en estas revistas, los préstamos, que son analizados atendiendo a su uso y papel semántico-pragmático. Mientras que en el presente estudio se abordan las otras dos clases de palabras distinguidas por su formación: aquellas creadas con mecanismos patrimoniales del español y las formadas por elementos patrimoniales y foráneos, que adquieren un carácter híbrido. Por tanto, en las siguientes páginas se va a analizar la presencia de estos tipos de unidades en dichas revistas desde el punto de vista de la creación léxica y de la función discursiva, en relación con el carácter y finalidad de las revistas consultadas.

\footnotetext{
${ }^{1}$ Las secciones generales de las tres revistas son las siguientes: Woman: Exprésate, Inspírate fiesta, Reportajes, Especial regalos, Planes, Moda, Shopping, Ocio, Belleza, Living (estas se dividen en subsecciones; Glamour: Editorial, Mailbox, Backstage, Glamourama, Hot Topic, Es glamour, Tendencias, Moda, Belleza, Chica de moda, Hallazgos, Compras, Irresistible, Deseos, Espíritu, Stars, Generación, Hombres, Reportaje, Creadores, Diario de redacción, Arte, Objetivo, Astro, Look de la estilista, Must have, Reportaje, Seducción, Divas, Compras, Buenos precios, Favoritos, Guía de belleza, A fondo, Vida Glamour, Pareja, debate, Encuesta, Psico, Flechazos, Club, Agenda, Planeta; Cosmopolitan: Cosmo News, Fashion \& Shopping, Manual de hombres, Cosmo Look, Tú, tú y tú, Especial Party, Amor y sexo, Moda, Belleza, Body Love, Salud, Y además... (estas se dividen en subsecciones).
} 
Las unidades léxicas que se exponen proceden de un corpus compilado mediante la consulta manual de las revistas citadas anteriormente durante el año 2011 y los cuatro primeros meses de 2012. La mayor parte de las unidades presentan una documentación frecuente en el corpus (establecida a partir de tres apariciones de una voz y en distintas revistas); una porción inferior se atestigua con menor frecuencia (un máximo de tres ocurrencias en las distintas revistas o en una de ellas), y una sección de las unidades se documenta una sola vez.

El análisis de este tipo de léxico que singulariza tales revistas se desarrolla seguidamente a partir de la citada clasificación de las unidades en aquellas creadas con mecanismos patrimoniales y las que responden a una formación híbrida. Dentro del primer grupo se observan formaciones que representan la mayor parte de los procesos de creación léxica del español; mientras que, entre las formaciones híbridas, se dan creaciones de carácter variado.

\section{CREACIONES LÉXICAS DE FORMACIÓN PATRIMONIAL}

\subsection{Formaciones por prefijación}

El procedimiento de la prefijación es muy recurrente en estas revistas para formar palabras que denominan determinados referentes caracterizados por el rasgo que expresa el prefijo, el cual, con frecuencia, intensifica o destaca lo dicho. Así, es abundante el uso pragmático de prefijos intensivos, los cuales aportan una mayor carga intencional, emotiva o cuantitativa del contenido significativo de una palabra, ponderando la cualidad de la base y reflejando así un matiz añadido (Martín García, 1998). En este sentido, se observan formaciones con el prefijo mini- ${ }^{2}$. Según el DRAE (2001), este elemento posee el significado de 'pequeño' o 'corto'; si bien, de acuerdo con Méndez Santos (2011: 103), en la formación de palabras relacionadas con la moda, tal prefijo es parafraseable como 'muy pequeño' en la mayoría de los casos. Los tres valores semánticos del prefijo se aprecian en los ejemplos siguientes, en los que dicho elemento se adjunta a distintos lexemas para denominar prendas de vestir y otros objetos caracterizados por su tamaño pequeño ${ }^{3}$, como minicamiseta, minicamisón,

\footnotetext{
${ }^{2}$ Varela y Martín (1999: 5025) incluyen este afijo en los prefijos intensivos de tamaño o cantidad, junto con maxi-, hiper-, macro-, mega- y super-. Mientras que consideran prefijos intensivos de cualidad ultra-, archi-, extra-, hiper-, re-, sobre-, super-, casi/cuasi-, entre-, medio-, semi-, infla-, hipo- y sub-.

${ }^{3}$ Rodríguez Ponce (2002: 168) afirma que la adjunción de este prefijo se da con preferencia sobre bases sustantivas, y Miranda (1994: 94) comenta su rentabilidad en el lenguaje comercial y periodístico.
}

NoRMAS. REVISTA DE ESTUdIOS LINGÜÍSTICOS HISPÁNICOS, NÚMERO 2 (AÑO 2012):

http://www.uv.es/normas

(ISSN 2174-7245) 
minishort, minicepillo, minicolección, minineceser, mini onda, minivestido o mini vestido ${ }^{4}$ :

1. Rozando casi la costura, en la colección de primavera de Jil Sander encontramos un homenaje a la luz y al colorido, con propuestas que combinan largas e importantes faldas de fiesta con minicamisetas que realzan la figura (Glamour, febrero 2012, 25).

2. Minicamisón con print de rosas y short de Yamamay (34,90 €) (Glamour, febrero 2012, 219).

3. Si quieres mostrarle tu atractivo con la ropa, los minishorts, más cortos que nunca, son la propuesta más hot de la próxima primavera (Glamour, febrero 2012, 148).

4. Beauty tip. No olvides meter un minicepillo para mantener el pelo desenredado (Cosmopolitan, julio 2011, 183).

5. El británico, artífice de las revistas de tendencias 'Danzed \& Confused' y 'Another Magazine', es responsable de No_Code, una minicolección de calzado trendy que hará las delicias de hipsters y devotos de la firma (Woman, marzo 2012, 236).

6. Hemos reunido un minineceser con las herramientas de los maquilladores. Te sorprenderá su precisión y la facilidad de uso (Woman, marzo 2011, 273).

7. Efecto ola. Pásate al moldeado chic (nada que ver con los fritos ochenteros). La mini onda viene disciplinada y brillante para una melena con extra de sexy (Cosmopolitan, abril 2012, 196).

8. Brillante drapeado. Minivestido (Woman, diciembre 2011, 157).

9. Te hemos recomendado mil veces que te compres un mini vestido estampado, pero pasamos a la acción: ¡te lo regalamos! (Cosmopolitan, julio 2011, 46).

\footnotetext{
${ }^{4}$ Hemos optado por marcar en negrita las voces comentadas para respetar en el ejemplo su escritura en el texto original, ya sea en letra redonda, cursiva o entre comillas.
}

NORMAS. REVISTA DE ESTUDIOS LINGÜÍSTICOS HISPÁNICOS, NÚMERO 2 (AÑO 2012):

http://www.uv.es/normas

(ISSN 2174-7245) 
En todos los casos puede deducirse el significado de la voz a partir de su formación, si bien la denotación exacta adquiere matices ya que el prefijo actualiza un sentido de proporción, cantidad o tamaño pequeño diferente en función de la palabra a la que se adjunte. Así, encierra el significado de 'corto' o 'muy corto' en formaciones como minicamisón, minivestido o minishort; mientras que actualiza el sentido de 'pequeño' o 'muy pequeño' en minicepillo, minineceser y mini onda, y en el vocablo minicamiseta recoge ambos valores, ya que denomina una camiseta corta y ajustada. En cuanto a minicolección, el prefijo aporta el sentido de cantidad pequeña. En algunos casos, tales significados se constatan mediante la imagen del objeto, que acompaña al texto en la revista concreta. Por otro lado, se observa cómo la creación minivestido presenta la variante con el afijo separado de la base (mini vestido), al igual que en mini onda, lo que constituye un aspecto recurrente, como se observará más adelante.

También es elevada la presencia del afijo de tamaño maxi-, opuesto semánticamente a mini-, para denotar una magnitud mayor o un mayor alcance o complejidad (Varela y Martín, 1999: 5025). Así se adjunta a distintos lexemas en denominaciones de productos propios de la moda actual, que lanza determinadas prendas y complementos con un nuevo formato de grandes dimensiones. Tal es el caso de maxiplataformas, maxigargantilla, maxianillo, maxi-brazaletes, maxi jersey, maxi falda, maxi bolso:

10. Maxiplataformas de aire retro. Inspiradas en los diseños de los años 70, con suela de madera o corcho, y casi inalcanzables -con cuñas de hasta 14 centímetros (Woman, junio 2011, 110).

11. Maxigargantilla metálica con abalorios Asos (58 €) (Woman, diciembre 2011, 82).

12. Este maxianillo con toque retro te sentará de miedo (Cosmopolitan, diciembre 2011, 181).

13. Tamaño XXL. Los maxi-brazaletes serán la atracción de tus muñecas y darán fuerza a tus estilismos monocolor en tonos maquillaje (Woman, diciembre 2011, 38).

14. No esperes al verano para ponértelo. ¿El secreto? Un maxi jersey retro (Glamour, febrero 2012, 132).

15. Llévalo con maxi faldas para conseguir el efecto capa (Glamour, febrero 2012, 134). 
16. Exóticos. Pulseras, maxi bolsos, sandalias tobilleras... Añade un toque desenfadado a tu fondo de armario con accesorios que dan color (Woman, marzo 2012, 183).

Rodríguez Ponce (2002) relaciona la menor productividad del prefijo mini- con respecto a maxi- con el hecho de que se crean primero las palabras con el elemento mini- y, después, se generan las parejas mediante maxi-. Si bien, por el momento, según el corpus elaborado, este caso se observa únicamente en la pareja minifalda/maxifalda, ya que este segundo vocablo se usa desde hace poco, por analogía al primero.

Se constata la variación formal en la combinación de los prefijos mini- y maxicon la base, puesto que se presentan tanto adjuntados a esta como unidos con un guion, y separados gráficamente, generando, en estos dos últimos casos, una forma incorrecta según la ortografía del español (RAE 2011: 420) ${ }^{5}$. Este aspecto podría relacionarse con que el usuario tal vez concibe dichas formas con un valor más autónomo que el propio de los prefijos, debido a su carga denotativa bien delimitada (aunque adquiere matices relativos a las dimensiones, a la longitud o a la cantidad, según el referente que se nombre), y a su carga expresiva, vinculada al valor intensivo. De hecho, los prefijos mini- y maxi- se emplean con frecuencia como unidades independientes yuxtapuestas a sustantivos a los que especifican con un valor adjetival, para intensificar el sentido de dimensiones o cantidad grandes o pequeñas atribuidas a lo denotado por el sustantivo. Esto se observa en ejemplos como formato mini, prendas mini, presupuesto mini, detalles mini, precio mini, complementos maxi, plataforma maxi, ondas maxi, formato maxi:

17. Destápate y transforma tus t-shirts a un formato mini (Cosmopolitan, julio 2011, 30).

18. Se llevan en clave retro como en Rochas, en forma de pantalones sofisticados como Rodarte o prendas mini como en Kane (Woman, marzo 2012, 52).

19. Aunque haya un montón de eficaces novedades, no olvides los ingredientes clásicos: la urea ultrarreparadora, la glicerina superhidratante, el karité nutritivo... Mimos con presupuesto mini (Cosmopolitan, julio 2011, 192).

20. Espejos grandes y detalles mini (Glamour, noviembre 2011, 317).

21. Lujo a precios mini (Glamour, febrero 2012, 46).

\footnotetext{
${ }^{5}$ Guerrero Salazar y Núñez Cabezas (2002: 78) advierten la tendencia en el lenguaje periodístico a la presentación de las voces formadas por mini- con un guion de enlace con la base.
}

NoRMAS. REVISTA DE ESTUdIOS LINGÜÍSTICOS HISPÁNICOS, NÚMERO 2 (AÑO 2012):

http://www.uv.es/normas

(ISSN 2174-7245) 
22. Los diseñadores han convertido la lencería en una de las reinas de la pasarela. Póntela como prenda de 'streetwear' y con complementos maxi (Cosmopolitan, julio 2011, 156).

23. Salón con plataforma maxi, de Céline (820 €) (Glamour, febrero 2012, 75).

24. Las propuestas que vienen para el cabello son de impacto: ganan las ondas maxi, el efecto despeinado se impone y arrasa el color block (Glamour, febrero 2012, 148).

25. Los brazaletes se presentan en formato maxi (Woman, marzo 2012, 229).

Según lo expuesto, cabría considerar la generación de un nuevo uso y valor adjetival de las unidades mini y maxi, que va cobrando difusión en la lengua.

En estas revistas también se emplea el elemento micro- para hacer referencia a productos actuales caracterizados por su tamaño marcadamente inferior. Por ejemplo en micro accesorios, donde el prefijo ${ }^{6}$, separado de la base como en los casos anteriores, intensifica el tamaño pequeño propio de los accesorios referidos:

26. Segundas líneas, piezas de marroquinería y micro accesorios te dan la oportunidad de llevarte a casa una pieza de las firmas más deseadas por mucho menos (Glamour, febrero 2012, 46).

Son recurrentes los afijos hiper- y super-, considerados también como prefijos muy productivos en español (NGLE: 667). Según Varela y Martín (1999: 5026), el primero denota grado máximo de lo expresado por el lexema base, y el segundo, un grado medio ${ }^{7}$. Esta función se constata en creaciones ocasionales ${ }^{8}$ de adjetivos como superprotectoras, supersensual, supersaludable, superchic, hiperfemenino, donde las respectivas bases se cargan del matiz de 'en grado sumo' (DRAE, 2001), relacionado con la cualidad, para super-; o de 'muy', 'altamente' (Méndez Santos, 2011: 132) o 'en

\footnotetext{
${ }^{6}$ Seguimos la consideración de este elemento como prefijo, de acuerdo con Varela y Martín (1999: 5025) y la $N G L E$ (2011: 665), en la que también se indica que esta forma, al igual que otras, se considera elemento compositivo de origen culto en unos análisis, y prefijo, en otros.

${ }^{7}$ La NGLE (2011: 670) los clasifica como prefijos gradativos: super- de intensidad e hiper- de grado máximo.

${ }^{8}$ Seguimos la distinción planteada en Estornell Pons (2009) entre creaciones ocasionales y neologismos propiamente dichos.
}

NoRMAS. REVISTA DE ESTUdIOS LINGÜÍSTICOS HISPÁNICOS, NÚMERO 2 (AÑO 2012):

http://www.uv.es/normas

(ISSN 2174-7245) 
grado máximo’ (NGLE 2009: 670), para hiper- ${ }^{9}$. El uso del prefijo en estas formaciones cumple, pues, la función discursiva de intensificar la cualidad de la palabra base y aportar expresividad, en ocasiones para persuadir sobre el producto que se describe:

27. Te presentamos los cosméticos más potentes del momento: Ringlet 07 de Redken $(20,45 €)$, una cera capilar que aporta un aroma supersensual a tu melena [...] (Cosmopolitan, julio 2011, 56).

28. No, no se trata de afrodisiacos, ni de recetas secretas para subyugarle, sino de alimentos que por sus propiedades nutritivas, además de equilibrar tu dieta y ser supersaludables (los nutrientes que te aportan son esenciales para el organismo) favorecen tu look (Cosmopolitan, julio 2011, 216).

29. Piel de terciopelo con fórmulas superprotectoras (Glamour, julio 2011, 132).

30. Busca un aspecto gracioso, sofisticado y superchic. Así es el moreno de este verano. Olvídate de los bronceados mutantes y sé selectiva. Céntrate en tu mirada y cubre tus labios con una pátina de oro (Cosmopolitan, abril 2012, 194).

31. Flores. ¡Que sean oversize! Mézclalas con cuadros de colores hiperfemeninos (Cosmopolitan, julio 2011, 56).

32. Elige tonos llamativos y coloridos estampados para unos diseños hiperfemeninos (Woman, marzo 2012, 184).

En la misma línea, se emplea el prefijo ultra- adherido a distintos lexemas para expresar el grado máximo de lo denotado por la base (Varela y Martín, 1999: 5026), creando así unidades esporádicas como ultrasexy, ultraligera, ultraeficaces, ultrarrápidos, ultrarresistente, ultranaturales, ultrarreparadora, ultrafemenino, ultrabrillantes, ultraprecisión:

33. Aparentan sencillez, pero su efecto es ultrasexy (Glamour, febrero 2011, 122).

\footnotetext{
${ }^{9}$ La NGLE (2009: 670) diferencia los prefijos que expresan intensidad positiva en gradativos $y$ escalares (re-, super-, archi-), grado máximo (extra-, hiper-, requete-) y grado medio (semi-, entre-, medio-).
}

NORMAS. REVISTA DE ESTUdIOS LINGÜÍSTICOS HISPÁNICOS, NÚMERO 2 (AÑO 2012):

http://www.uv.es/normas

(ISSN 2174-7245) 
34. Para acertar, usa una base ultraligera. Eso sí, tanto en primavera como en verano, apuesta por un fondo con protección; además de unificar el tono, actúan como escudo contra la radicación (Woman, junio 2011, 202).

35. Cóctel de activos. Son las armas secretas de la cosmética: ampollas concentradas y ultraeficaces (Woman, junio 2011, 204).

36. Así que no temas depilarte con cremas o cuchillas, dos métodos ultrarrápidos (Glamour, julio 2011, 136).

37. Los últimos desfiles han estado inundados de manicuras casual y ultranaturales (Cosmopolitan, julio 2011, 196).

38. Ultrarresistentes al agua. Por último, un consejo rápido: en la playa estarás más protegida frente al sol y al sudor con un protector solar capaz de resistir hasta dos veces más al agua. Confía en los productos de Garnier Delial y Germaine de Capuccini (Glamour, julio 2011, 140).

39. Aunque haya un montón de eficaces novedades, no olvides los ingredientes clásicos: la urea ultrarreparadora, la glicerina superhidratante, el karité nutritivo... Mimos con presupuesto mini (Cosmopolitan, julio 2011, 192).

40. Ultrafemenino (titular de página en Woman, diciembre 2011, 80).

41. Los looks más atrevidos: esmoquin blanco o pitillos y americanas ultrabrillantes (Woman, diciembre 2011, 120).

42. Esponja dobla cara. Ultraprecisión (Woman, marzo 2012, 273).

El significado de este prefijo puede parafrasearse como 'extremadamente' (Méndez Santos, 2011: $130{ }^{10}$, de modo que intensifica al máximo la cualidad significada por los lexemas sexy, ligera, eficaz, rápido, natural, resistente, reparadora, femenino, brillante y precisión, realzando el valor de lo que se refiere en el texto. Este

${ }^{10}$ El DRAE (2001) registra, para este prefijo, los significados de 'más allá de', 'al lado de' y 'exceso'. Sería este último el relacionado con el valor intensivo apuntado, si bien también se asocia con el valor original de 'del lado de allá' (Alemany 1920: 212, apud Méndez Santos 2009: 130).

NORMAS. REVISTA DE ESTUDIOS LINGÜÍSTICOS HISPÁNICOS, NÚMERO 2 (AÑO 2012):

http://www.uv.es/normas

(ISSN 2174-7245) 
afijo suele asociarse a un registro culto y a lenguajes especializados (Varela y Martín, 1999); sin embargo, su frecuencia en las revistas consultadas indica una progresiva extensión de su uso a textos de la lengua común. Y, al igual que otros comentados anteriormente, este prefijo también se presenta separado de la base, como en la forma ultra brillante:

43. Un velo ultra brillante. «Si tienes la piel rosada, elige tonos con reflejos rosa palo o lila; para pieles doradas, oro rosa» (Woman, marzo 2012, 276).

Asimismo, se observa el prefijo extra- en formaciones como extragrande, extralimpia, extraplanas, en las que aporta el significado de 'sumamente' (DRAE, 2001), de excepcionalidad o superioridad (Varela y Martín García, 1999: 5013):

44. Capazo XXL. Llegan los días de playa... y shopping bajo el sol. ¿Tu mejor aliado? Un cesto de rafia extragrande (Woman, junio 2011, 32).

45. Nuestro paso a paso exige una piel extralimpia. Nada más levantarte elimina las impurezas nocturnas con la ayuda de un gel espumoso (Cosmopolitan, julio 2011, 70).

46. Combinan a la perfección con altísimos tacones o con sandalias extraplanas, pero siempre con un estilo muy glam (Woman, marzo 2012, 183).

Dicho afijo se considera intensivo en Guerrero Salazar (2007: 360) y gradativo de grado máximo en la NGLE (2011: 670); y conviene destacar este tipo de creaciones, ya que la productividad de tal elemento habitualmente se relaciona con el lenguaje científico y no con la lengua general ( $N G L E, 2009$ : 690). Además, el valor positivo que cobra el prefijo en formaciones como las ejemplificadas contrasta con el valor negativo emergente cada vez más común en el lenguaje periodístico, en casos como extrapresupuestario o extrafiscal (Méndez Santos, 2011: 83) ${ }^{11}$. En los ejemplos aducidos se comprueba cómo el prefijo se une a adjetivos para incidir en las características del producto, sirviendo a la eficacia comunicativa. También en este afijo se observa la tendencia a separar tales elementos de la base, como se ilustra en

47. Cazadoras de lujo. La parte superior del chándal — sí, has leído bien, chándal — llega a las pasarelas en su versión más posmoderna. Con cremallera, extra volumen, negación.

${ }^{11}$ Méndez Santos propone para este prefijo un fenómeno de traslación desde la locación hacia la NoRMas. REVISTA DE ESTUdIOS LINGÜÍSTICOS HISPÁNICOS, NÚMERO 2 (AÑO 2012):

http://www.uv.es/normas

(ISSN 2174-7245) 
entallada, en tejidos satinados o en punto roma, lo importante es cómo las combinas (Woman, marzo 2012, 52).

Asimismo, se dan en estas revistas casos de creación de palabras con prefijos no intensivos, para transmitir eficazmente un determinado significado en el texto, como el de un momento concreto en el siguiente enunciado, mediante un prefijo de valor temporal:

48. TIP: La solución para saltarte la loción corporal post baño, es utilizar un gel de ducha con parafina hidratante (Cosmopolitan, diciembre 2011, 68).

Se observa, una vez más, la tendencia anormativa a separar el prefijo de la base, posiblemente debida a la conciencia del hablante sobre la carga denotativa del afijo.

O bien para comunicar significados relacionados con la oposición, a través del prefijo anti-, por ejemplo, como en los casos que siguen:

49. ¡Quiero operarme! Guía antipánico. Tu deseo es operarte, pero tras los últimos acontecimientos lo normal es que sientas miedo. De la mano de expertos damos respuestas a tus dudas para que no tengas pánico a dar el paso si es lo que quieres (Cosmopolitan, abril 2012, 124).

50. Escribe tu anti-lista y procura cumplirla. El domingo por la tarde, siéntate un rato tranquila y escribe una lista con las cosas que vas a ignorar completamente la semana que empieza [...](Cosmopolitan, abril 2012, 227).

En el primero, la creación antipánico trata de transmitir de manera transparente y expresiva el significado 'que combate el pánico relativo a las operaciones de cirugía estética', con lo que se da el valor de anulación del referente de la base (Varela y Martín, 1999: 5019). En el segundo, la nueva voz encierra el sentido que se define en el contexto, de modo que no es un sentido predecible a partir de la forma, ya que el significado del propio prefijo no incide sobre el significado directo de la base sino sobre un significado implícito de esta, el de 'lista de cosas que no hay que hacer', actualizado por el contexto. Con esta formación, pues, se crea una unidad que expresa enfáticamente la idea generada. Y, en ambos casos, puede comprobarse la vacilación en la adjunción del prefijo a los distintos lexemas.

Así pues, el mecanismo lexicogenésico de la prefijación resulta altamente productivo en las revistas consultadas, tanto para la formación de voces denominativas de nuevos objetos o variantes propios de la moda actual, como para la creación de

NoRMAS. REVISTA DE ESTUdIOS LINGÜÍSTICOS HISPÁNICOS, NÚMERO 2 (AÑO 2012):

http://www.uv.es/normas

(ISSN 2174-7245) 
palabras esporádicas que transmitan eficazmente lo que se pretende comunicar en el enunciado, práctica en la que destaca el uso de prefijos intensivos. La eficacia de tales procesos de prefijación radica, en cualquier caso, en la transparencia semántica de la unidad creada, necesaria para la comprensión del significado de la voz.

\subsection{Formaciones por sufijación}

La creación léxica con sufijos es menos frecuente en estas revistas que la formación con prefijos, a diferencia de la tendencia común, que sitúa la sufijación como el mecanismo morfológico más productivo en el uso general. Las formaciones con sufijos documentadas responden, en unos casos, a creaciones ocasionales para un texto concreto, como las unidades cosquillear y rockanrollear:

54. Nueva terapia. ¡Cosquilléate! No se trata de reír sin parar. Pero sí de conseguir relax absoluto. Las cosquillas son una terapia novedosa, placentera y muy beneficiosa para conectar con uno mismo (Woman, diciembre 2011, 218).

55. Para rockanrollear ponte camisas con remates metálicos y pantalones campana (Cosmopolitan, abril 2012,33).

El sufijo - ear se añade a la palabra cosquillas para crear un verbo con el significado de 'hacer cosquillas'; mientras que, en rockanrollear, la creación transmite un sentido más impreciso, no especificado en el contexto, ya que podría ser el de 'adoptar la estética del rock and roll' o bien el de 'asistir a un concierto de rock and roll' ${ }^{12}$. Ambas voces se generan para hacer referencia a una acción o concepto de una manera original y en un tono lúdico.

En otros casos, las creaciones léxicas con sufijos no presentan tal carácter esporádico ya que se constatan en varias revistas. Así ocurre con el verbo accesorizar, formado mediante el sufijo verbalizador -izar, que se adhiere al sustantivo accesorio con el valor resultativo de 'dotar o proveer de x o de sus características' (Serrano Dolader, 1999: 4697), para transmitir el significado de dotar de accesorios (entendidos como complementos, DRAE, 2001) a la indumentaria, femenina en este caso:

51. Accesoriza tu LBD. El Little Black Dress es un básico que no puede faltar en tu armario por su capacidad de tener muchas vidas dependiendo de los accesorios que utilices (Cosmopolitan, diciembre 2011, 130).

\footnotetext{
${ }^{12}$ Para este sufijo se consideran diferentes valores según las bases y los contextos (véase, por ejemplo, Rifón, 1997; Serrano Dolader, 1999).
}

NORMAS. REVISTA DE ESTUdIOS LINGÜÍSTICOS HISPÁNICOS, NÚMERO 2 (AÑO 2012):

http://www.uv.es/normas

(ISSN 2174-7245) 
52. Accesorízate. El mylar, plástico reflectante utilizado en envases de bebidas, transforma tus gadgets cotidianos en objetos de culto (Glamour, febrero 2012, 44).

53. Accesorízalo con piezas brillantes como cadenas doradas, pulseras con tachuelas y piedras, bolsos metálicos (Woman, marzo 2012, 182).

En relación con este verbo, se produce la creación del sustantivo correspondiente, accesorista, denominativo de la persona que sabe seleccionar y combinar los accesorios de la manera más adecuada:

56. ¿Quieres la mejor guía de zapatos y bolsos de esta temporada? Una de nuestras lectoras te enseña cómo, cuándo y dónde ponértelos para convertirte en una accesorista profesional (Cosmopolitan, abril 2012, 184).

Tanto este nuevo sustantivo como el verbo del que deriva están cobrando difusión en el ámbito de la moda, lo que marca estas voces con un valor eminentemente referencial.

\subsection{Formaciones por composición}

El mecanismo de la composición resulta recurrente para las innovaciones léxicas detectadas en las revistas de consulta. Dentro de este proceso se distinguen distintos tipos. Uno de ellos son los llamados compuestos propios, léxicos u ortográficos, caracterizados por la amalgama fonológica de sus constituyentes y la unidad morfológica del conjunto (Val Álvaro, 1999: 4761). Por ejemplo, se crea la voz quemacalorías, compuesta de verbo más nombre, como un modificador apositivo con valor de instrumento, referido a un determinado tipo de música:

57. Música quemacalorías. ¿Qué música elegir si quieres quemar calorías? La que se escucha en los gimnasios [...] tiene unos bits, o pulsaciones por minuto, determinados, que son los ideales para quemar el máximo de calorías (Glamour, noviembre 2011, $50)$.

Se observa cómo esta formación resulta semánticamente transparente y enfatiza lo dicho en el enunciado.

NORMAS. REVISTA DE ESTUDIOS LINGÜÍSTICOS HISPÁNICOS, NÚMERO 2 (AÑO 2012):

http://www.uv.es/normas

(ISSN 2174-7245) 
También se forma chocoadicción, con la unión de dos sustantivos que suman sus significados ${ }^{13}$ para denotar, de forma expresiva, la adicción al chocolate:

58. Chocoadicción. Eva Mendes. Confiesa que se comería una tabla de madera con tal de que estuviera recubierta de chocolate (Cosmopolitan, abril 2012, 235).

Por otro lado, se constatan creaciones léxicas por composición culta, como las que integran el formante-manía, que se comporta como un elemento compositivo culto en la formación de nuevas palabras con el sentido de 'obsesión' o 'inclinación vehemente por algo' (Méndez Santos, 2011: 327). Así en leopardomanía, topmanía, danzamanía, insectomanía. Las dos primeras son creaciones ocasionales que denotan, respectivamente, la tendencia «obsesiva» en la moda actual al uso de un tipo de estampado (el que imita la piel del leopardo) y de una clase de prenda, los tops:

59. De pies a cabeza, la leopardomanía sigue siendo el estampado rey (Glamour, noviembre 2011,36).

60. ¡Enseña el ombligo! Anota este concepto porque va a revolucionar tus looks veraniegos. Topmanía. Destápate y transforma tus t-shirts a un formato mini (Cosmopolitan, julio 2011, 30).

En la misma línea, se forma esporádicamente danzamanía para hacer referencia a la alta oferta de espectáculos y exposiciones de danza en un lugar y un presente concretos:

61. Ríndete a la danzamanía (Glamour, febrero 2012, 89).

También, se recurre a la formación ocasional de insectomanía para expresar la proliferación actual de formas que imitan a los insectos en el sector de la bisutería:

62. Insectomanía. Las joyas más chic de la temporada revolotean de look en look para accesorizar una primavera muy espectacular (Woman, marzo 2012, 264).

\footnotetext{
${ }^{13}$ En esta unión, el segundo constituyente complementa al primero, que actúa como núcleo (véase Val Álvaro, 1999: 4783).
}

NORMAS. REVISTA DE ESTUDIOS LINGÜÍSTICOS HISPÁNICOS, NÚMERO 2 (AÑO 2012):

http://www.uv.es/normas

(ISSN 2174-7245) 
La creación de estas voces con el constituyente -manía posee, pues, un valor connotativo derivado del propio formante, por lo que estas unidades resultan expresivas, enfatizan el contenido del enunciado añadiendo cierto tono jocoso y distendido, acorde con el carácter de las revistas estudiadas.

También se constatan creaciones por composición patrimonial con acortamientos modernos (Méndez Santos 2011: 310). Por ejemplo, la voz tecnoadictas, donde tecnofunciona como acortamiento de tecnología y se une a adictas para nombrar a las mujeres adictas a las nuevas tecnologías, con un valor connotativo y economía lingüística:

63. Todo por mi iPad. Se ha convertido en el objeto de deseo de las tecnoadictas; si no lo tienes, no existes. Pero... ¿dónde demonios colocarlo? Te proponemos algunas ideas diferentes (Woman, marzo 2012, 52).

Asimismo, responden a este tipo de formaciones las voces creadas con el elemento eco-, de gran recurrencia en las revistas. Según Méndez Santos (2011: 299), dicho elemento no es un prefijo o pseudoprefijo, sino una forma moderna acortada (de ecológico) o tema culto que pasa a formar parte de procesos morfológicos posteriores, como la composición ${ }^{14}$. Desde su significado originario de 'medio ambiente', 'ecología', 'ecológico' (Clave, 2003: 720), se han generado dos nuevos valores, como el de 'no contaminante' y el de 'respetuoso con el medio ambiente, sostenible', y en algunas voces su significado se relacionaría con el de 'reciclaje', por lo que ha adquirido un valor nuevo diferente del valor registrado en el DRAE y otros diccionarios de referencia. En la mayoría de los textos documentados, el prefijo se adhiere a un lexema con el primero de los valores citados, como en eco-excursión, ecoviajera, ecoviaje, ecotienda:

64. Un paseo en helicóptero sobrevolando las Montañas Rocosas, un crucero culinario hacia el Polo Sur o una eco-excursión en Costa Rica (Glamour, febrero 2011, 261).

65. Cómo ser una ecoviajera. Deja de lado la idea de un viaje de lujo con estilismos made in Gossip Girl, asientos de primera clase en el avión y descanso a pie de playa. Tu misión en estas vacaciones es reducir la huella ambiental y cultural, respetar la naturaleza y las costumbres, y ayudar al desarrollo económico y social de tu destino (Cosmopolitan, julio 2011, 106).

\footnotetext{
${ }^{14}$ La autora argumenta, entre otras razones, que este elemento, al igual que otros como narco, bio, vídeo o $\operatorname{logo}$, «provocan una variación de significado que no es una particularidad atribuible a los afijos», si bien no descarta que, con el tiempo, estos elementos puedan fijarse en una posición y se asimilen funcionalmente a los afijos (Méndez Santos, 2011: 299).
}

NoRMAS. REVISTA DE ESTUdIOS LINGÜÍSTICOS HISPÁNICOS, NÚMERO 2 (AÑO 2012): 
66. ¿Por qué es un ecoviaje? Gracias a tu colaboración se podrán cubrir algunas necesidades básicas demandadas por las poblaciones (Cosmopolitan, julio 2011, 107).

67. Ecotienda. Compra limpia. Los nuevos establecimientos apuesta por el medio ambiente, ahorran un 30\% de energía y disminuyen la emisión de CO2 (Woman, marzo 2012, 254).

Se observa que con el formante eco- se crean palabras para denominar un tipo de excursión, de viaje, de viajera y de tiendas determinadas, de carácter ecológico fundamentado en distintos factores mencionados en el contexto. La voz novedosa ecotienda, además, supone una etiqueta para una nueva clase de establecimientos comerciales marcados por dicha conciencia ecologista.

Y con el citado formante también se generan adjetivos para calificar productos que cumplen con el carácter ecológico, como en la creación eco-responsable:

68. Buscan eficacia con resultados visibles y, últimamente, que sean productos ecoresponsables, respetuosos con el medio ambiente y con su propia piel (Glamour, noviembre 2011, 176).

Puede comprobarse en este ejemplo que dicho elemento prefijal también fluctúa en cuanto a su unión gráfica a la base.

En otros casos, como se verá más adelante, el elemento eco aparece como acortamiento de ecológico, en calidad de unidad aislada con el mismo valor semántico.

Por otro lado, se encuentran creaciones de compuestos denominados impropios, imperfectos, posléxicos o pseudocompuestos, los cuales ofrecen menor integridad fonológica y morfológica ya que no tienen unidad acentual, la flexión de género y número se realiza en el primer constituyente o en los dos y se da la posibilidad de derivación del primer elemento en los compuestos nominales. En los compuestos impropios se incluyen tradicionalmente los compuestos formados por la yuxtaposición de dos nombres y los integrados por dos lexemas unidos gráficamente con un guion (Val Álvaro, 1999: 4762; Gómez Clemente y Rodríguez Guerra, 2003: 132), a los que

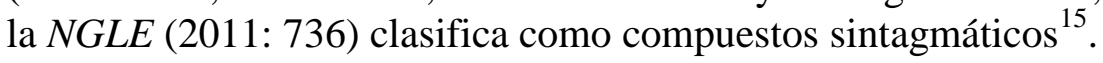

\footnotetext{
${ }^{15}$ Algunos autores sitúan las formaciones unidas con guión como un tipo especial de compuestos impropios a medio camino entre los formados por amalgama y los que presentan una estructura sintáctica yuxtapuesta (Gómez Clemente y Rodríguez Guerra, 2003: 133). Por otra parte, determinados estudios incluyen en los compuestos impropios los formados por un sintagma, a los que denominan compuestos sintagmáticos, mientras que la NGLE concibe estas formaciones como compuestos sintácticos o locuciones nominales. Otros autores, en cambio, opinan que se tata de mecanismo lexicogenésico aparte entendido como sintagmación (Observatori de Neologia, 2004).
} 
La composición por unión de dos nombres con un guion se observa en unidades como vestido-suéter, bolso-cartera, foto-blogueras, retro-sexy, rústico-chic, vegetariano-creativos. Vestido-suéter y bolso-cartera han surgido en el ámbito de la moda para denotar una nueva clase de prenda de vestir y de complemento respectivamente, como se desprende del significado de las voces:

69. Vestido-suéter. Es uno de los must de Isabel Marant. Se trata de camisetas de béisbol más largas y ceñidas (Woman, junio 2011, 125).

70. Killah. Expresa tu lado más divertido a través de sus bolsos-cartera de alegres estampados (killah.com) (Glamour, julio 2011, 172).

El significado de ambas unidades resulta transparente a partir de su formación, en la que se aprecia una relación semántica de determinación o subordinación entre los lexemas formantes, ya que el segundo constituyente describe al primero, mediante la adición de propiedades características del segundo constituyente ${ }^{16}$ : se nombra un vestido con propiedades de suéter (por su forma y tamaño) y un bolso con propiedades de cartera (por su forma, tamaño y función).

También por composición se crea el vocablo foto-bloguera, mediante la forma foto como acortamiento de fotografía, y la derivación patrimonial del anglicismo blog, que origina bloguera $^{17}$. Se trata de una voz usada en este texto con una función denominativa, cuyo significado no resulta tan transparente como los anteriores, dado que la lectora debe interpretar, con la ayuda del contexto, que este vocablo designa a personas que hacen fotografías para colgar en $\operatorname{blog} s^{18}$ :

71. Su estilo es objetivo de foto-blogueras (Woman, marzo 2012, 236).

La unidad retro-sexy se crea integrando el elemento retro- y el adjetivo sexy, para expresar un significado concreto también predecible a partir de la formación:

${ }^{16}$ Siguiendo a Val Álvaro (1999), quien considera los compuestos marcados por esta relación semántica como compuestos endocéntricos subordinativos, frente a los compuestos endocéntricos coordinativos y los compuestos exocéntricos. En líneas similares, Arntz y Pitch (1989: 76) y Cabré (1992: 189) hablan de una relación semántica de determinación.

${ }^{17}$ Esta palabra alterna en tales revistas con la forma bloggera, castellanización del inglés blogger para crear el correlativo femenino: «Y no te pierdas la colección de lencería que ha diseñado la bloggera The Cherry Blossom Girl para Etam... Oh, là là! (Cosmopolitan, abril 2012, 36) (Cosmopolitan, abril 2012, 33)».

${ }^{18}$ Se ha señalado la tendencia a formaciones de compuestos con el elemento foto-, clasificados como compuestos endocéntricos subordinativos con segundo nombre nuclear (Val Álvaro, 1999: 4787).

NoRMAS. REVISTA DE ESTUdIOS LINGÜÍSTICOS HISPÁNICOS, NÚMERO 2 (AÑO 2012):

http://www.uv.es/normas

(ISSN 2174-7245) 
72. Coleta retro-sexy. «Esta coleta tiene un efecto XXL gracias al cardado en la parte superior y resulta igual de sexy que una melena peinada con volumen en las puntas», nos dice Marco Santini, creador de estos looks [...] (Cosmopolitan, julio 2011, 162).

El formante retro-, originalmente un elemento compositivo, se usa actualmente como lexicalizado con un valor normalmente especificativo de un nombre al que complementa, para hacer referencia 'estilo que recupera una moda pasada' ${ }^{19}$. En este caso, se combina con el adjetivo sexy para especificar un tipo de coleta que presenta conjuntamente los atributos de ambos constituyentes.

En la voz rústico-chic se unen dos adjetivos para expresar en una sola forma un contenido semántico, derivado de la suma de los componentes rústico y chic, de modo que la unidad nombra una clase de estilo que reúne las dos características:

73. Otro motivo para ir: su restaurante de tapas y bar de cócteles Aspen Social Club, de un estilo rústico-chic en honor a la estación de esquí. Aquí se reúne la gente guapa (Woman, diciembre 2011, 112).

La palabra vegetariano-creativos se crea esporádicamente para calificar un tipo de tipo de preparación gastronómica de carácter vegetariano e inspirada en la llamada cocina creativa:

74. Apúntate a los talleres de costura que una vez al mes organiza el restaurante Teresa Carles, de Barcelona, y que combina con un brunch para degustar sus platos vegetariano-creativos (Woman, diciembre 2011, 196).

Esta unidad aúna, pues, dos conceptos en un solo significante, que presenta un significado transparente definido, nuevamente, por una relación de coordinación entre los lexemas.

Es recurrente en las revistas comentadas la formación todo-en-uno, compuesta de tres lexemas unidos gráficamente con guion:

75. Un cuidado todo-en-uno. Después de popularizarse entre las mujeres asiáticas por el resultado excepcional que consigue sobre la piel, llega a Occidente como un producto único que trata, cubre imperfecciones, protege, controla los brillos y unifica la tez de inmediato (Woman, diciembre 2011, 222).

19 Información extraída de «El curioso idioma de la moda», sección La revista. Cultura y tendencias, ocio y espectáculos, gente y televisión, 20 minutos, 11-5-2012, pág. 13. Otra definición es «el regreso de una moda pasada que hoy está de vuelta», de $E l A B C$ de la moda, http://www.esmas.com/mujer/belleza/especialmoda/327413.html. 
76. Todo-en-uno Fitness: más de 700 ejercicios, 40 entrenamientos, contador de calorías, body tracker y reproductor de música. ¿Se puede pedir más? (Cosmopolitan, diciembre 2011, 143).

Con esta forma se acota en una sola expresión la idea de concentración de diversas funciones, usos o características en un solo producto, originándose una forma solidaria con un significado único (Alvar Ezquerra, 1993: 28), que suele yuxtaponerse a un sustantivo al que complementa. La unidad resulta, así, rentable discursivamente.

Y también se emplean en este tipo de discursos unidades compuestas por la yuxtaposición de dos nombres separados gráficamente, como sandalia joya:

77. Sandalias joya. Lujo a tus pies. Pisan con fuerza los modelos básicos de tiras a ras de suelo. ¿Lo más cool? Con piedras, brillos, strass, metales... Las it girls más trendys ya las llevan (Woman, marzo 2012, 52).

Su significado se interpreta fácilmente, y se genera por una relación semántica de determinación o subordinación del segundo elemento con respecto al primero (Val Álvaro, 1999: 4785), dado que se describe una sandalia con la adición de propiedades de joya, debido a los materiales que la componen. Se forma así una unidad denominativa de un objeto concreto.

De modo que en este tipo de discurso se documentan diversidad de formaciones compuestas, con fines eminentemente denominativos, ya sea de novedades actuales, o ya como denominación ocasional de un referente o concepto mencionado en el texto. No se observa en el corpus, por tanto, la tendencia señalada en algunos estudios, según la cual, entre los distintos tipos de compuestos, son la aglutinación de verbo más sustantivo y la yuxtaposición de sustantivo más sustantivo las combinaciones más rentables en la actualidad (Guerrero Salazar, 2007: 369).

\subsection{Acortamientos léxicos}

En los textos consultados también aparecen con frecuencia voces que son acortamientos léxicos ${ }^{20}$, entendiendo por tal el acortamiento de una unidad léxica preexistente mediante la reducción fónica de fonemas o sílabas, generalmente iniciales o finales, de tal modo que se genera una nueva forma léxica pero con el mismo

${ }^{20} \mathrm{El}$ acortamiento también se conoce como abreviación, abreviamiento, forma acortada o truncamiento.

NORMAS. REVISTA DE ESTUdIOS LINGÜÍSTICOS HISPÁNICOS, NÚMERO 2 (AÑO 2012):

http://www.uv.es/normas

(ISSN 2174-7245) 
significado de la unidad original, si bien en ocasiones conlleva cierto valor connotativo o adquiere una marca de uso, ya sea coloquial, argótico, etc. Este mecanismo está motivado por la necesidad de manifestar un valor apreciativo y por la tendencia a la economía en el uso del lenguaje (Almela, 1999: 202). Así se constata en unidades como lipo, gine, ofi, semi, acortamientos de liposucción, ginecólogo, oficina, semipermanente, respectivamente, usadas con un valor estilístico para imprimir al texto cierto tono informal, familiar, moderno, juvenil y menos serio, de acuerdo con el carácter de estas revistas:

78. Técnicas lipo a examen. En plena temporada alta de los tratamientos contra la grasa, Francia ha prohibido su práctica. Valoramos su situación con expertos que los realizan en nuestro país (Glamour, julio 2011, 164).

En este ejemplo, el uso de lipo en lugar de liposucción resulta más moderno y resta seriedad y carga connotativa a la palabra técnica originaria.

El enunciado siguiente ilustra la preferencia del acortamiento gine, por su rasgo más familiar y cercano:

79. ¡Alerta! Consulta con tu gine si... tus cambios de humor son demasiado bruscos y tienen efectos muy negativos en tus relaciones, en tu trabajo y en tu vida diaria (Cosmopolitan, diciembre 2011, 291).

Igualmente, en este otro ejemplo el acortamiento ofi resulta más acorde con el tono informal y moderno que presenta el texto:

80. Sé la más cool de la ofi con los kits de papelería de Muji. Se acabó tener que pedir siempre la grapadora (Cosmopolitan, diciembre 2011, 179).

También el acortamiento prota aporta un estilo más coloquial y familiar que su correspondiente protagonista, como en el ejemplo:

81. Los cincuenta y la camisa serán 'protas' de tu armario (Cosmopolitan, abril 2012, 159).

Y en el contexto que sigue se emplea la forma semi como acortamiento de semipermanente, en cuanto que forma más cercana y económica de referirse a un tipo de manicura caracterizada por una durabilidad y acabado dependientes del gel: 
82. Puedes aplicar una laca normal y después retirarla con un quitaesmaltes sin acetona. La 'semi' permanecerá intacta (Woman, diciembre 2011, 214).

Las marcas tipográficas de este acortamiento indican la conciencia de novedad y coloquialidad de la forma por parte de la redactora.

También es común el acortamiento mini como nueva forma de referirse a la minifalda, en busca de variedad y un tono juvenil:

83. Sustituye la maxifalda por una mini rescatada de los 90 más minimalistas e incorpora notas cítricas, doradas y mucho rojo frenesí en los complementos (Glamour, febrero 2012, 123).

Asimismo, muy recurrente es el acortamiento de la unidad sintagmática top model en las voces top y supertop (aquí incorpora el prefijo intensivo), que aportan economía lingüística y un estilo novedoso:

84. En solo tres semanas ha alcanzado la categoría de top: ocupa el puesto número 5 en models.com — baremo que cataloga el éxito del gremio — [...] (Woman, marzo 2012, 127).

85. La supertop Daria Werbowy, ejemplo de belleza natural y sofisticada, descubre el secreto del maquillaje más veraniego: embellece las facciones con bases que reflejen la luz y con polvos bronceadores (Glamour, julio 2011, 126).

Resultan altamente frecuentes las formas bio y eco como acortamientos generalmente yuxtapuestos a un nombre al que especifican con los significados de 'ecológico', 'biológico', 'natural', 'no artificial', 'reciclado', ampliando el carácter polisémico de estos elementos (Méndez Santos, 2011: 369). Según el vocablo al que acompañe la unidad, tales significados pueden concretarse en otros, definidos por Méndez Santos (2011: 401-402) para el funcionamiento de estas formas como acortamientos modernos que dan lugar a palabras compuestas, pero que también se observan en su uso como sustantivo ${ }^{21}$. En las revistas citadas aparecen ejemplos de este tipo, donde las voces bio y eco califican, con la citada denotación, a distintos referentes. Así, con bio se especifican, en el primer ejemplo, una clase de bombones caracterizados

${ }^{21}$ Para el elemento bio-, la autora indica los valores de 'de modo natural, sin agentes químicos artificiales', 'no contaminante', 'procedente de material reciclado' y 'procedente de la agricultura ecológica'. Para eco-, se señalan los valores de 'no contaminante', 'respetuoso con el medio ambiente', 'con un desarrollo sostenible' y 'relacionado con el reciclaje' (Méndez Santos, 2011: 401, 402).

NoRMAS. REVISTA DE ESTUdIOS LINGÜÍSTICOS HISPÁNICOS, NÚMERO 2 (AÑO 2012):

http://www.uv.es/normas

(ISSN 2174-7245) 
por su elaboración natural, sin agentes químicos artificiales; y, en el segundo, un tipo de elementos del mismo carácter:

86. Mima tu paladar con los bombones bio y de diseño de chocolate orgánico (Glamour, febrero 2011, 282).

87. Una de sus gafas, realizada con elementos bio, salvaguardará el bosque atlántico, en Brasil. Parte de los beneficios se donarán a The Nature Conservacy (Woman, marzo 2012, 38).

Con eco, se documentan unidades como materiales eco, alpargatas eco, moda eco, hoteles eco, gastronomía eco, cuidados eco, musa eco, en las que se aprecia el uso recurrente del elemento eco concretado en matices según los casos:

88. Materiales eco. Los clásicos canastos de rafia comparten protagonismo con nuevas shopping-bags de mimbre, yute y lino orgánico (Woman, junio 2011, 32).

89. Romanas flúor, esclavas exóticas, stilettos brillantes, plataformas retro, alpargatas eco... Este verano empieza a vestirte por los pies (Woman, junio 2011, 108).

90. El must para vivir un verano de altura. Mimbre natural, madera barnizada, corcho orgánico, yute o esparto tintado en colores vibrantes... La moda eco se sube a las pasarelas (Woman, junio 2011, 109).

91. 3 hoteles muy eco (Cosmopolitan, julio 2011, 107).

92. Gastronomía eco al sur de Francia. Recorres las tres comarcas agrícolas y rurales del Aubrac (una verde meseta al suroeste francés) y descubre el encanto de su campo chic, un fenómeno turístico y cultural basado en la economía ecológica de la zona (Cosmopolitan, julio 2011, 107).

93. Los cuidados eco de las celebrities. Lo natural no es una tendencia, es una necesidad. Nos lo cuentan estas guapísimas beauty coach (Glamour, noviembre 2011, 174).

94. Angela Lindvall. Musa eco. En la Provenza y como portavoz de la segunda fragancia solidaria de DKNY, la modelo nos recibe en exclusiva y nos explica cómo trabaja cada día para transformar el mundo (Glamour, febrero 2012, 156).

NoRMAS. REVISTA DE ESTUdIOS LINGÜÍSTICOS HISPÁNICOS, NÚMERO 2 (AÑO 2012):

http://www.uv.es/normas

(ISSN 2174-7245) 
Y se atestigua el empleo aislado del acortamiento, sin complementar a ningún nombre, como en el siguiente contexto:

95. El verde musgo en el desfile de Tortea o los vestidos cascada de Angel Schlesser dan prueba de que la moda española es más eco que nunca (Glamour, febrero 2012, 54).

El asentamiento en la lengua de esta forma acortada se observa también en que da lugar a derivados mediante la adjunción de sufijos como -ista, en ecoísta, que se crea con valor ocasional en este enunciado para transmitir el sentido de "partidaria de la ecología':

96. Una «ecoísta» a seguir. Ni por imagen personal, ni por pasatiempo. Lo suyo con la Madre Natruraleza y los proyectos sostenibles es pasión (Glamour, febrero 2012, 158).

Del carácter novedoso de la voz da cuenta también su marcación tipográfica con las comillas.

\subsection{Formaciones por acronimia}

La acronimia, también llamada cruce léxico o entrecruzamiento (Varela, 2005), consiste en la formación de una palabra a partir de normalmente dos unidades léxicas, estando representada, al menos una de ellas, por un fragmento (una o más sílabas) de su significante: la primera, por el fragmento inicial de su significante, y la segunda, por el fragmento final del suyo (Casado Velarde, 2007: 384). Para algunos autores la acronimia solo se da cuando se combinan en un lexema nuevo un fragmento inicial de una unidad léxica y un fragmento final de otra unidad léxica (Almela, 1999: 206). Mientras que en la NGLE (2011: 713) se considera la acronimia como una subclase dentro de los compuestos propios o universales.

En el discurso de estas revistas aparecen creaciones por acronimia, si bien con menos frecuencia que otras. Tal es el caso de la palabra esporádica cibelespacio, procedente de Cibeles (formante de la construcción Pasarela Cibeles) y espacio, como juego lingüístico motivado por el vocablo ciberespacio, con un fin altamente expresivo $^{22}$ :

${ }^{22}$ Guerrero Salazar (2007: 205) y Méndez Santos (2011: 409) señalan el carácter humorístico o lúdico de algunas formaciones constituidas mediante el cruce léxico.

NORMAS. REVISTA DE ESTUDIOS LINGÜÍSTICOS HISPÁNICOS, NÚMERO 2 (AÑO 2012):

http://www.uv.es/normas

(ISSN 2174-7245) 
97. Perdidos en el cibelespacio. Cada temporada tienes una cita en la semana de la moda madrileña plagada de encuentros, peculiaridades, fiestas... Nuestro invitado, el periodista de mida Josie, te desvela todos los secretos de backstage de la pasarela española (Glamour, febrero 2012, 32).

También se constatan acrónimos con fines referenciales, como psiconutrición, surgido recientemente a partir de psicología y nutrición para denominar un nuevo sistema de reorientación alimentaria que se presenta en una de las revistas consultadas:

98. Equilibra tu dieta para siempre con el nuevo método basado en la psiconutrición (Glamour, febrero 2012, 144).

En esta creación, se deduce un sentido aproximado a partir de la forma, si bien el significado concreto lo aporta el texto que la recoge.

Por último con respecto a este apartado dedicado a las creaciones patrimoniales, hay que señalar que la mayoría de las unidades mostradas no aparecen en el texto con marcas tipográficas, a pesar de tratarse de voces nuevas o de creaciones ocasionales para un texto dado, o, en algunos casos, de formas de carácter coloquial. Únicamente se presentan marcadas las unidades leopardomanía, eco-responsables, semi, top, prota, ecoísta y cibelespacio, en las que la letra cursiva o las comillas - según los casosseñalan que se trata de una nueva forma o creación, ya sea porque se use como forma nueva de expresar algo ya existente, como top o semi; ya porque se haya creado a propósito para transmitir con expresividad, originalidad o eficacia determinados significados en el texto, como los casos de leopardomanía, eco-responsables, ecoísta; bien como forma lúdica y original de referirse a un hecho, según se aprecia en la creación ciberespacio; o también como uso informal, para el caso de prota.

\section{UNIDADES DE FORMACIÓN HÍBRIDA}

Como se anticipó al principio, el léxico de las revistas consultadas se nutre también de unidades formadas por la combinación de un elemento patrimonial con otro de carácter foráneo, generalmente del inglés, lengua moderna y de prestigio, con preponderancia en ciertos ámbitos, como el de la moda.

Las combinaciones que se registran en el corpus hasta el momento responden a los mecanismos de la afijación y la composición. Se observan casos de prefijación como ultra-hot y ultra hot, extra hot o super party: 
99. Rizos ultra-hot. ¡Como lo oyes! Los rulos vuelven más fuertes que nunca. «Ya sabemos que suena muy antiguo, pero son el secreto de unos bucles perfectos y un volumen extra hot», dice Santini (Cosmopolitan, julio 2011, 165).

100. El glamour ultra hot de Versace se vuelve low cost esta temporada (Glamour, noviembre 2011, 146).

101. Mira a Paris Milton, fiestera irredenta que cada Nochevieja aparca al novio de turno para montar una super party con Lindsay Lohan, Kim Kardashian y compañía (Cosmopolitan, diciembre 2011, 146).

Al préstamo hot se le añaden prefijos intensivos para intensificar significados como 'actual, nuevo, fresco, de moda,' y 'atractivo, sexy' ${ }^{23}$, con los que se usa este préstamo en el ámbito de la moda. Y el vocablo party, muy recurrente en estas revistas, recibe también la prefijación intensiva con el elemento super. Mediante tales creaciones se persigue, pues, intensificar el sentido de lo referido en el texto. Y, al igual que en las formaciones patrimoniales, se da vacilación en la unión del prefijo a la base o su separación con un guion o sin él, así como en la marcación tipográfica de la unidad, que varía en su presentación en cursiva, en la escritura en cursiva solo del préstamo y en la no marcación tipográfica, incluso en el mismo texto, como ilustra el segundo ejemplo.

También aparece algún caso de adición de un sufijo a una palabra extranjera, como el vocablo fashionista, que se documenta con frecuencia en estos textos como denominación de un concepto concreto. Esta voz responde a la adición del sufijo agentivo -ista sobre el préstamo fashion para designar a una persona involucrada en la moda, seguidora de esta, ya sea por motivos profesionales o $\mathrm{no}^{24}$ :

102. Infalible. El blazer tipo esmoquin es el mejor aliado de las fashionistas de medio planeta. Invierte en uno blanco y crearás tendencia (Woman, diciembre 2011, 36).

Asimismo, se documentan formaciones como cuponing, análoga a otras formaciones como puenting o edredoning ${ }^{25}$. Se trata de una novedad léxica creada de la

${ }^{23}$ Significados procedentes del Collins Cobuild Advanced Lerner's English Dictionary y del Cambridge Dictionary (<http://dictionary.cambridge.org/dictionary/english-spanish/hot?q=hot $>$ ), así como de diversas fuentes de Internet.

${ }^{24}$ Definición extraída de <http://www.mundochica.com/diccionario-de-moda/>. Este significado se relaciona con valores del sufijo -ista como el de designaciones de profesionales, descripciones del carácter de una persona, designaciones de participantes o miembros de un grupo (Santiago y Bustos, 1999: 4572), o actitud (Almela, 1999: 112).

${ }^{25}$ Puenting se recoge en el DPD (RAE, 2005) con remisión a la forma patrimonial recomendada puentismo; y edredoning la documenta en un caso Méndez Santos (2011: 175) a partir de la prensa.

NORMAS. REVISTA DE ESTUDIOS LINGÜÍSTICOS HISPÁNICOS, NÚMERO 2 (AÑO 2012):

http://www.uv.es/normas

(ISSN 2174-7245) 
adjunción del sufijo inglés -ing al lexema patrimonial cupón. Este vocablo cobra difusión en el uso para denominar una acción de marketing cuyo objetivo principal es incrementar las ventas de un producto a través de cupones de descuento ${ }^{26}$, y así aparece en textos de las revistas citadas al hablar de tales prácticas:

103. Si aún no practicas el cuponing hazte socia de Groupalia, Letsbonus o Groupon y compra servicios (peluquería, masajes, cenas, escapadas...) con descuentos de hasta el $70 \%$ (Glamour, febrero 2012, 75).

En este ejemplo, pues, la palabra responde a un fin mayormente denominativo.

Más frecuentes resultan las unidades creadas por la unión de un préstamo y una voz patrimonial generando un compuesto de carácter híbrido. Destacan, en una de las revistas, las formaciones de unidades compuestas a partir del anglicismo beauty, como beautyrespuestas y la variante beauty respuestas, beauty rituales o beauty tendencias:

104. Ahí van las beautyrespuestas a tus dudas. Cuélgalas en cosmopolitan.com.es ¡Publicamos las mejores! (Cosmopolitan, julio 2011, 76).

105. Ahí van las beauty respuestas a tus dudas (Cosmopolitan, abril 2012, 90).

106. Nuestra encuesta revela los 'beauty' rituales nocturnos que odian... ¡Toma nota! (Cosmopolitan, diciembre 2011, 68).

107. Beauty tendencias. Te enseñamos a ponerlas en práctica (Cosmopolitan, abril 2012, 159).

Estas combinaciones resultan esperables dada la alta frecuencia de uso del préstamo beauty en las revistas, principalmente en el caso de Cosmopolitan, lo que lleva a la coaparición del anglicismo con elementos patrimoniales. Se comprueba cómo en la creación de compuestos con el mismo préstamo se genera en un caso un compuesto propio, y, en otros, yuxtapuestos, dando lugar a variantes formales de una misma unidad; si bien hay que señalar la forma anormativa de beautyrespuestas en lo que a la unión de los constituyentes se refiere.

26 Información extraída de <http://www.marketing-movil-sms.com/tendencias-movil/cuatroconsejos-para-campanas-de-cuponing-movil/>.

NORMAS. REVISTA DE ESTUDIOS LINGÜÍSTICOS HISPÁNICOS, NÚMERO 2 (AÑO 2012):

http://www.uv.es/normas

(ISSN 2174-7245) 
Asimismo, aparecen compuestos impropios unidos por un guion como cóctel-girl, creado para designar de manera novedosa y estilística a una mujer que sabe preparar cócteles variados e innovadores:

108. ¿Has decidido dar una fiesta en casa? Conviértete en una cóctel-girl y sorprende a todos tus invitados con las copas más chic que hayan probado nunca. ¡Puedes hacerlo! (Cosmopolitan, diciembre 2011, 156).

O la formación men-manicura y pedicura, en la que el anglicismo men se une a un sintagma español para especificar la referencia de la manicura y pedicura aplicada a los hombres, en busca de estilo y economía lingüística:

109. Men-manicura y pedicura. Hacerse las uñas no es sólo cosa de chicas. Cada vez son más los hombres que acuden a un profesional para que les dé un buen repaso a sus dedos (Cosmopolitan, abril 2012, 70).

Otro ejemplo es preppy chic, que integra la palabra chic, ya incorporada al español, y el préstamo preppy, denotativo de un estilo determinado ${ }^{27}$; de modo que la unidad se crea para denotar un estilo concreto en el que se mezclan el preppy y el chic:

110. Desde que René Lacoste lanzó la chemise que catapultó la maison, la firma no ha perdido su estética preppy chic. El estilo deportivo, fresco y juvenil, su santo y seña, se incrementa según avanzan las colecciones del diseñador (Woman, marzo 2012, 238).

También se aprecia la constancia del elemento manía (considerado como elemento compositivo culto) para crear compuestos de unidades híbridas, como demuestra la formación ocasional skatemanía. En ella, la palabra inglesa skate se une con dicho elemento para referirse a la creciente moda actual del uso de un determinado tipo de monopatín ${ }^{28}$ :

${ }^{27}$ Relativo al original estilo de los estudiantes de las instituciones de élite norteamericanas, caracterizado por su comodidad y elegancia al tiempo que cierto aire deportivo. Actualmente este estilo recibe otras inspiraciones y diseños (información extraída de <http://es.paperblog.com/que-es-el-estilopreppy-390046/>, revista En femenino).

${ }^{28}$ Esta es la correspondiente traducción del inglés skate en el contexto presentado.

NORMAS. REVISTA DE ESTUDIOS LINGÜÍSTICOS HISPÁNICOS, NÚMERO 2 (AÑO 2012):

http://www.uv.es/normas

(ISSN 2174-7245) 
111. New trend. Skatemanía. Seguro que has visto por las calles de tu ciudad skates más largos de lo habitual, como si fueran oversize. ¡Son lo más! Apúntate a este nuevo estilo que nació en California en los años 70, y que sigue hoy la people más cool del planeta (Cosmopolitan, diciembre 2011, 36).

De estas unidades compuestas, solo se presenta con marcas tipográficas el caso de 'beauty' rituales, en que el préstamo aparece entre comillas. El hecho de no marcar las demás voces podría obedecer al carácter híbrido de la formación, por el que se desestimaría la necesidad de su marca dado que no es una voz completamente foránea, principalmente en el caso de los compuestos propios como beautyrespuestas o skatemanía. No obstante, en la medida en que se trata de creaciones esporádicas, o de unidades neológicas como fashionista, deberían escribirse marcadas tipográficamente, lo que lleva a relacionar esta carencia con la práctica inconstante y, en general, anormativa, que se da en estas revistas a la hora de presentar formalmente los neologismos, las creaciones esporádicas y los préstamos en general ${ }^{29}$. En cuanto a la transparencia semántica de las unidades híbridas expuestas, queda subordinada a los conocimientos de inglés que posean las lectoras, lo que puede dificultar la comprensión de alguna de las voces.

\section{CONCLUSIÓN}

En los textos de las revistas analizadas destacan usos léxicos particulares como los que se han mostrado en estas páginas. Aparecen formaciones con mecanismos morfológicos patrimoniales como denominaciones de nuevos referentes de la realidad actual, por ejemplo elementos de la moda. Y también se hace uso de dichos mecanismos para la creación de unidades esporádicas que denominen un concepto o referente concreto en un determinado texto, y así se recurre a procesos como la prefijación, la sufijación, la composición, el acortamiento y la acronimia. De todos ellos, el más frecuente es la prefijación, principalmente por el uso reiterado de la prefijación intensiva, con el fin de enfatizar lo dicho y transmitir eficazmente determinados valores en el texto, relacionados con el fin último de este tipo de revistas. El proceso de la prefijación también destaca por la vacilación observada en las tres revistas en la presentación del prefijo, ya que en ocasiones se adjunta al lexema base, en otras aparece unido con un guion y, en otras, separado, de manera anormativa. Asimismo, llama la atención en cuanto a los prefijos el uso de las formas maxi- y mini-, a menudo

${ }^{29}$ Cabe recordar que el uso y presentación de los préstamos en las revistas citadas se aborda en un estudio paralelo que se encuentra actualmente en prensa. También deseamos destacar el riguroso análisis de Sanmartín Sáez (2009) por su aportación al reconocimiento del neologismo desde una perspectiva contrastiva, sobre todo, en lo que afecta al préstamo entre lenguas en contacto, y por su reflexión sobre el concepto de comunidad de habla como factor esencial para la consideración del neologismo como tal. 
yuxtapuestas al lexema en forma de aposición, lo que indica un nuevo valor de dichos elementos. En cuanto a la sufijación, menos frecuente, se observan creaciones para expresar originalmente conceptos dados. Por otra parte, la composición resulta un mecanismo productivo en este tipo de textos para generar unidades denotativas de referentes y conceptos nuevos, y de otros preexistentes, a través de distintas clases de compuestos como los llamados compuestos propios y los impropios, tanto unidos con guion como yuxtapuestos. También llama la atención el uso de acortamientos léxicos, que imprimen al texto un tono informal y moderno, en consonancia con el carácter de las revistas. Y, entre ellos, destacan las formas bio y eco, de creciente difusión con un sentido específico generado recientemente. Por último, la acronimia se da con poca frecuencia, ya sea para formaciones ingeniosas como juego de palabras, ya como alguna unidad neológica denotativa de una nueva realidad.

El otro tipo de voces presentado en estas páginas abarca aquellas formadas por la combinación de un elemento patrimonial y otro foráneo, por medio de la prefijación, la sufijación y la composición, generalmente como formas nuevas y estilísticas de expresar determinados conceptos y referentes, en relación con las connotaciones de la lengua inglesa; si bien aparece alguna unidad con función meramente denominativa.

Buena parte de estas clases de voces que caracterizan tales revistas desde el punto de vista léxico no se presentan con las marcas tipográficas que les corresponderían por tratarse de unidades creadas ad hoc, unidades neológicas, voces de tono informal, o palabras parcialmente patrimoniales. En este sentido, y teniendo también en cuenta la comentada separación que presenta el prefijo de la base en muchas de las unidades, se observa en estas revistas una práctica poco normativa en cuanto a la presentación formal de una porción de su léxico. Y es que, a partir del análisis de este y de la consulta atenta de los textos de dichas revistas, se concluye que, en ellas, se prima, sobre la corrección normativa, el uso de un lenguaje eficaz, que acompañe al fin promocional de su contenido, proyectando una imagen y efectos determinados en las lectoras, que deben identificarse con la revista y sentirse atraídas por lo que se presenta en ellas. El léxico, pues, debe servir a dicho fin, expresando novedades, aportando novedad y frescura, y enfatizando ciertos significados, para comunicar con eficacia. 


\section{REFERENCIAS BIBLIOGRÁFICAS}

Alarcos LlORACH, Emilio (1992): «Consideraciones sobre el neologismo», en Gómez Font, Alberto y Pedro García Domínguez, comp., El neologismo necesario, Madrid, Fundación EFE, 17-30.

Almela PÉREZ, Ramón (1999): Procedimientos de formación de palabras en español, Barcelona, Ariel.

Alvar EZQUERRA, Manuel (1993): La formación de palabras en español, Madrid, Arco/Libros.

Alvar EZQUERRA, Manuel (1999): «El neologismo: caracterización, formación y aceptabilidad», en González Calvo, José Manuel, M. ${ }^{a}$ Luisa Montero Curiel y Jesús Terrón González, eds., V Jornadas de Metodología y Didáctica de la Lengua Española: el neologismo, Cáceres, Universidad de Extremadura, 39-66.

ARNTZ, R. y H. PichT (1995): Introducción a la terminología, Humanes, Fundación Germán Sánchez Ruipérez, Madrid, Pirámide.

BlAnCO, Luisa (1997): «El lenguaje de la publicidad», en Henríquez, M. ${ }^{\text {a }}$ do Carmo y Miguel Ángel Esparza, eds., Estudios de lingüística, Departamento de Filología Española Universidad de Vigo.

CABré, M. ${ }^{a}$ Teresa (1992): La terminologia. La teoria, els métodes, les aplicacions, Barcelona, Antártida/Empuries.

CABrÉ, M. ${ }^{a}$ Teresa (1994): A l'entorn de la paraula. Vol. 2., Valencia, Universitat de València.

CAmbridge University: Cambridge Dictionaries on line. Cambridge Advanced Lerner's English Dictionary, University Press: <http://dictionary.cambridge.org/dictionary/english-spanish/hot?q=hot $>$.

Casado Velarde, Manuel (2002): «Acortamientos léxicos, formación de siglas y

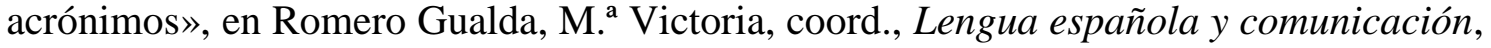
Barcelona, Ariel, 379-391.

ESTORNEll PONS, María (2009): Neologismos en la prensa: criterios para reconocer y caracterizar las unidades neológicas, Valencia, Universitat de València, Quaderns de Filologia, Anejo n. ${ }^{\circ} 70$.

Gómez Clemente, Xosé María y Alexandre Rodríguez Guerra, coord. (2003): «Neoloxismos na lengua xornalistica galega», en Gómez Clamente, Xosé María y Alexandre Rodríguez Guerra (coord.): Neoloxia e lengua galega: teoría e práctica, Vigo, Universidade de Vigo, 95-167.

GUERRERo SAlAZAR, Susana (2007): La creatividad en el lenguaje periodístico, Madrid, Cátedra. 
Guerrero SAlazar, Susana y Emilio Alejandro NúÑEz CABeZAS (2002): Medios de comunicación y español actual, Málaga, Aljibe.

Maldonado González, Concepción (dir.) (2003): Diccionario de uso del español actual. Clave, Madrid, SM.

MARTín GARcíA, Josefa (1998): «Los prefijos intensivos del español. Caracterización morfo-semántica», Estudios de Lingüística, 12, 103-116.

MÉNDEZ SANTOS, M. ${ }^{a}$ Carmen (2011): Los neologismos morfológicos del español en el lenguaje de la prensa: estudio de la lexicogénesis del español a través de la prensa del español actual, Editorial Académica Española.

MiRANDA, José Alberto (1994): La formación de palabras en español, Salamanca, Ediciones Colegio de España.

OBSERVATORI DE NEOLOGIA (2004): Llengua catalana $i$ neologia. Institut Universitari de Lingüística Aplicada, Universitat Pompeu Fabra, Barcelona, Meteora.

ReAl ACADEMia EsPaÑola (2009): Nueva Gramática de la lengua española, Espasa-Calpe. Calpe.

REAL ACADEMIA ESPAÑola (2011): Ortografía de la lengua española, Espasa-

Real AcAdemia EsPañola: Diccionario de la lengua española, Avance de la vigésima tercera edición: 〈http://www.rae.es〉.

RIFón, Antonio (1997): Pautas semánticas para la formación de verbos en español mediante sufijación, Santiago de Compostela, Universidad de Santiago de Compostela.

RodríGueZ Ponce, M. ${ }^{a}$ Isabel (2002): La prefijación apreciativa en español, Cáceres, Universidad de Extremadura.

SANMARTÍN SÁEZ, Julia (2009): «El neologismo desde una perspectiva contrastiva: entre lo cognitivo y lo lexicográficos», Revista de Investigación Lingüística, 12, 147 175 .

SANTiago, Ramón y Eugenio Bustos (1999): «La derivación nominal», en Bosque, Ignacio y Violeta Demonte, dir., Gramática descriptiva de la lengua española. 3. Morfología, Madrid, Espasa, 4505-4594.

SERRANO DOLADER, David (1999): «La derivación verbal y la parasíntesis», en Bosque, Ignacio y Violeta Demonte, dir., Gramática descriptiva de la lengua española. 3. Morfología, Madrid, Espasa, 4683-4756.

TORRES, Rosario (2007): «Revistas de moda y belleza: el contenido al servicio de la forma bella», Ámbitos, 16, 213-225. 
VAl Álvaro, J. Francisco (1999): «La composición», en Bosque, Ignacio y Violeta Demonte, dir.: Gramática descriptiva de la lengua española. 3. Morfología, Madrid, Espasa, 4757- 4843.

VARELA ORTEGA, Soledad y Josefa MARTín García (1999): «La prefijación», en Bosque, Ignacio y Violeta Demonte, dir., Gramática descriptiva de la lengua española. 3. Morfología, Madrid, Espasa, 4993-5040.

\section{Corpus}

Woman, el lujo de ser mujer. Grupo Zeta, Ediciones Reunidas s.a.

Glamour. La revista de moda y belleza más vendida. Ediciones Condé Nast S.A.

Cosmopolitan. Fun, Fearless, Female. Cosmo España, G. y J. Publicaciones Internacionales S. L. y CIA. 